Gynecologic and

Obstetric Investigation
Gynecol Obstet Invest 2009;67:187-194

DOI: $\underline{10.1159 / 000187650}$
Received: April 22, 2008

Accepted after revision: October 22, 2008

Published online: December 20, 2008

\title{
Anorectal Function Testing and Anal Endosonography in the Diagnostic Work-Up of Patients with Primary Pelvic Organ Prolapse
}

\author{
Annette G. Groenendijk ${ }^{a}$ Erwin Birnie $^{b, e}$ Guy E. Boeckxstaens ${ }^{c}$ \\ Jan-Paul W. Roovers ${ }^{d}$ Gouke J. Bonsel ${ }^{\text {b, e }}$ \\ a Department of Gynecology and Obstetrics, Onze Lieve Vrouwe Hospital, Amsterdam, Departments of \\ bSocial Medicine/Public Health Epidemiology, ' Gastroenterology and Hepatology, and ${ }^{\mathrm{d}}$ Gynecology and \\ Obstetrics, Academic Medical Center, University of Amsterdam, Amsterdam, and ${ }^{\mathrm{e}}$ Institute of Health Policy and \\ Management, Erasmus Medical Center, Rotterdam, The Netherlands
}

\section{Key Words}

Anorectal function testing $\cdot$ Defecation disorders ·

Endosonography $\cdot$ Pelvic organ prolapse

\begin{abstract}
Aim: To study the pathophysiology of defecation disorders in patients with primary pelvic organ prolapse (POP) and the diagnostic potential of anorectal function testing (AFT) including endosonography in the work-up of these patients. Methods: 59 Patients were evaluated with a validated questionnaire, clinical examination, AFT and endosonography. Results: Women with POP showed lower squeezing pressure, postponed first sensation and desire, lower capacity and prolonged pudendal nerve terminal latency time compared to healthy controls (all $p<0.01$ ). Manometric findings did not differ significantly between patients with and without constipation. Patients with fecal incontinence had significantly lower resting and squeezing pressures than patients without fecal incontinence and an increased risk of an external sphincter defect (odds ratio $=12.75,95 \%$ confidence interval 2.40-66.67). Although digital rectal examination could quantify absent, decreased and normal squeezing pressure, the positive predictive value for external sphincter defects was low (0.32). Conclusion: AFT indicates the presence of neuromuscular damage of the anorectal re-
\end{abstract}

\section{KARGER}

Fax +4161306 1234 E-Mail karger@karger.ch www.karger.com (c) 2008 S. Karger AG, Basel

0378-7346/09/0673-0187\$26.00/0

Accessible online at:

www.karger.com/goi gion in patients with POP. AFT is not useful in the work-up of patients with POP and constipation, because it fails to discriminate between symptomatic and asymptomatic patients. In cases of fecal incontinence, AFT and endosonography are helpful to distinguish between functional and anatomical problems.

Copyright $\odot 2008$ S. Karger AG, Basel

\section{Introduction}

Pelvic organ prolapse (POP) with its accompanying function disorders often poses a diagnostic and therapeutic challenge. A rational diagnostic approach to bowel complaints has yet to be established. Bowel dysfunction may present as fecal incontinence, incomplete rectal emptying and the need for manual assistance, or excessive straining. The exact prevalence of bowel disorders in patients with POP, i.e. posterior wall prolapse, is unknown, but a high association between bowel disorders and POP has been reported $[1,2]$. A thorough understanding of the pathophysiology of pelvic floor function is essential in (surgical) treatment planning and in the counseling of patients with POP suffering from bowel dysfunction. According to the American Gastroenterology Association Clinical Practice, anorectal function

A.G. Groenendijk, MD

Department of Gynecology and Obstetrics

Onze Lieve Vrouwe Hospital

PO Box 95500, NL-1090 HM Amsterdam (The Netherlands)

Tel. +31 205993 477, Fax +31 205993 999, E-Mail a.g.groenendijk@olvg.nl 
testing (AFT) and endosonography might be useful in the work-up of patients with severe defecatory disorders [3]. Before recommending AFT including endosonography in the work-up of patients with POP and bowel complaints, we need to know more about the quality of these diagnostic interventions to discriminate between symptomatic and asymptomatic patients and to assess their diagnostic value in clinical decision making.

The aim of the study was to investigate the pathophysiology of constipation and fecal incontinence in patients with primary POP and to determine the potential role of AFT and anal endosonography in the diagnostic work-up of these patients. At first, we compared the findings at AFT and anal endosonography between patients with POP and women without POP (healthy control subjects). Secondly, we evaluated the potential of these tests to discriminate between patients with POP who had defecation symptoms and those with POP who did not have such symptoms. The study responds to the National Institutes of Health recommendations for further research to clarify the role of additional testing in the evaluation and management of POP $[4,5]$.

\section{Subjects and Methods}

\section{Patients}

Between January 2000 and January 2002, all women referred to the gynecology outpatient clinic of the Onze Lieve Vrouwe hospital (OLV hospital) with suspected primary POP were invited to participate in a study evaluating the diagnostics of POP. AFT and anal endosonography were performed as part of this study. Included were women who experienced a sagging sensation and/or micturition and defecation problems at least once a week, and in whom 1 of the compartments was at least stage II prolapse according to the POP-Q classification system [6]. Exclusion criteria were: gynecological pathology additional to the prolapse or previous prolapse surgery and/or hysterectomy. We enrolled $68 \mathrm{pa}-$ tients in the study; 5 patients dropped out (the extra diagnostic tests were too burdensome) and in 4 patients AFT or anal endosonography were not correctly carried out or read according to the study protocol. The study was approved by the medical ethics board of the OLV hospital and informed consent was obtained from all patients concerned.

\section{Study Design and Measurements}

We conducted a prospective, observational cohort study. The required examinations for the study were carried out during 2 visits. During the first visit to the gynecology outpatient clinic of the OLV hospital, patients completed a comprehensive health questionnaire and underwent a gynecological examination. At the second visit, AFT and anal endosonography were carried out at the department of gastroenterology of the Academic Medical Center. The questionnaire covered patient's characteristics, the prevalence and the severity of defecation symptoms as measured with the defecation distress inventory (DDI), a Dutch validated disease-specific questionnaire analogous to the urinary distress inventory and the colorectal-anal distress inventory [7-9].

The DDI consists of 15 items grouped into 4 domains: constipation, fecal incontinence, painful defecation and incontinence for gas. The scores in each of the DDI domains range from 0 to 100 , with a higher score indicating a greater symptom burden or more unfavorable impact on daily functioning. The 15 questions were developed after studying the literature and international definitions, interviewing patients who presented with constipation or fecal incontinence and by interviewing 3 experts in the field from the departments of surgery and obstetrics and gynecology of the University Medical Center Utrecht, The Netherlands. Eventually, a structured interview of the 15 selected items was held with 20 female patients. For this study, we used the Rome II criteria to identify patients with constipation [10]. Constipation was considered to be present when at least 2 of the following statements from the DDI were positively answered: less than 3 bowel movements a week; in more than $25 \%$ of cases straining to achieve bowel movement; sensation of incomplete evacuation; manual assistance at defecation, or a feeling of anal blockage. Patients were considered to have fecal incontinence if they experienced 1 of the following 4 inconveniences: incontinence for liquid stool, incontinence for formed stool, incontinence with urgency, or unnoticed loss of feces.

The severity of the prolapse was assessed according the POP-Q system by a study investigator (A.G.G.). The critical parameter in the POP-Q system in our case was point Bp, quantifying the severity of the posterior wall prolapse. The squeezing pressure of the anal sphincter was assessed by digital rectal examination.

AFT consisted of 4 components. During anal manometry, maximum anal resting pressure and maximum squeezing pressure were measured using a water-perfused sleeve catheter (Dentsleeve Pty Ltd., Parkside, S.A., Australia) connected to a polygraph (Synetics Medical, Stockholm, Sweden) and the data were stored on a PC. The data were analyzed using commercially available software (Polygram for Windows, Synetics Medical).

To assess rectal sensation volume, a highly compliant distending rectal balloon of $7 \mathrm{~cm}$ length was introduced in the rectum and gradually filled with air. Patients were asked to score at first sensation, first urge and the maximal tolerated volume. In addition, rectal and anal sensitivity to electrical stimuli were assessed using a ring electrode. Pudendal nerve terminal latency time (PNTLT) was determined using St Marks Pudendal Electrode (Dantec 13L40). Anal endosonography was performed to identify internal and external sphincter defects by ultrasound (Bruel and Kjaer Naerum, Denmark). Reference data from healthy controls were obtained from a UK study by Sun et al. [11]. The reference group consisted of 20 healthy females aged between 21 and 55 years (mean $43 \pm 2$ ). Five of the females were nulliparous. The equipment used and laboratory set up were the same as that at the department of gastroenterology of the Academic Medical Center.

Analysis

Due to a lack of studies on AFT outcomes in POP, a formal sample size could not be calculated. Instead we adopted a convenience sample of 59 patients with primary POP.

The prevalence and severity of bowel symptoms were described with conventional descriptive statistics. Differences in the means of quantitative outcome parameters were tested with Stu- 
dent's t test or analysis of covariance (ANCOVA), if appropriate. The effect of age and parity on squeezing pressure was assessed with multiple linear regression analysis. Diagnostic accuracy of digital rectal examination in the assessment of anal squeezing pressure was evaluated in terms of the proportion of correct test results, sensitivity, specificity, positive predictive value $(\mathrm{PV}+)$ and negative predictive value (PV-), using the outcome of anal manometry as the reference standard. Odds ratios (OR) and 95\% confidence intervals (CI) quantifying the association between sphincter defects and presence of fecal incontinence complaints were obtained with binary logistic regression analysis. SPSS for Windows v15.0 was used for data management and statistical analysis. $\mathrm{p}<0.05$ ( 2 sided) was considered statistically significant.

\section{Results}

The majority of patients had an overall POP-Q stage III $(68 \%, 40 / 59)$, but a posterior wall prolapse stage II (75\%, 44/59).

The main results of the DDI survey are shown in table 1 . Frequently reported complaints were feeling of incomplete defecation $(49 \%, 29 / 59)$ and false urge for defecation $(37 \%, 25 / 59)$. According to our criteria, there were 30 patients $(51 \%, 30 / 59)$ with constipation and 22 patients $(37 \%, 22 / 59)$ with fecal incontinence. Fifteen of the 22 patients with complaints of fecal incontinence had a perineal tear and in 2 of them it concerned a fourth degree perineal tear.

Table 2 shows the results of AFT in patients with primary POP compared to healthy controls. The results of AFT demonstrated that the mean resting pressure in women with POP was in the normal range. The mean squeezing pressure was significantly lower than the minimum value of the reference group.

Resting and squeezing pressures were not related to the stage of posterior wall prolapse $(\mathrm{p}=0.89$ and $\mathrm{p}=0.09$, respectively).

Volumetry showed a significantly higher mean volume for first sensation compared to healthy controls. Although the mean volume needed for first desire was within the range of the reference group, it was significantly higher than the mean volume found in healthy controls. The mean capacity was significantly lower in the patient group compared to healthy controls.

The mean rectal and anal sensitivity were significantly increased compared to the mean of the reference group, although they did not exceed the upper limit in 71.9 and $84.5 \%$ of cases, respectively. Mean PNTLT was significantly prolonged for both sides compared to healthy controls.
Table 1. Characteristics in 59 patients with primary POP

\begin{tabular}{|c|c|}
\hline \multicolumn{2}{|l|}{ Patient characteristics } \\
\hline Mean $\pm S D$ age (IQR), years & $55.4 \pm 10.1(17)$ \\
\hline \multicolumn{2}{|l|}{ Parity, n (\%) } \\
\hline $1-3$ & $34(58)$ \\
\hline$\geq 3$ & $25(42)$ \\
\hline Mean \pm SD BMI (range) ${ }^{a}$ & $25.3 \pm 4.3(18.4-39.1)$ \\
\hline \multicolumn{2}{|l|}{ Delivery profile ${ }^{\mathrm{b}}, \mathrm{n}$} \\
\hline Spontaneous delivery & 49 \\
\hline Forceps/vacuum & 6 \\
\hline Caesarean section & 4 \\
\hline \multicolumn{2}{|l|}{ Perineal trauma, n (\%) } \\
\hline No episiotomy or perineal tear & $14(24)$ \\
\hline Mediolateral episiotomy & $16(27)$ \\
\hline 2nd and 3rd degree perineal tear & $13(22)$ \\
\hline 4th degree perineal tear & $3(5)$ \\
\hline Episiotomy and perineal tear & $12(20)$ \\
\hline Unknown & $1(2)$ \\
\hline \multicolumn{2}{|l|}{ Mean \pm SD birth weight of largest } \\
\hline infant (range), g & $3,784 \pm 531(3000-5500)$ \\
\hline \multicolumn{2}{|l|}{ POP-Q points ${ }^{\mathrm{c}}, \mathrm{cm}$ score } \\
\hline $\mathrm{Aa}$ & $-0.13 \pm 1.10$ \\
\hline $\mathrm{Ba}$ & $2.08 \pm 2.08$ \\
\hline $\mathrm{C}$ & $-0.18 \pm 3.94$ \\
\hline gh & $4.03 \pm 1.05$ \\
\hline $\mathrm{Pb}$ & $2.76 \pm 0.68$ \\
\hline Ap & $0.16 \pm 1.46$ \\
\hline $\mathrm{Bp}$ & $0.22 \pm 1.59$ \\
\hline TVL & $8.05 \pm 1.08$ \\
\hline \multicolumn{2}{|l|}{ POP-Q overall stage, n (\%) } \\
\hline 0 & $0(0)$ \\
\hline I & $0(0)$ \\
\hline II & $15(25)$ \\
\hline III & $40(68)$ \\
\hline IV & $4(7)$ \\
\hline \multicolumn{2}{|l|}{ Defecation distress inventory, $\mathrm{n}(\%)$} \\
\hline Defecation $<3$ times a week & $9(15.3)$ \\
\hline Straining with defecation at & \\
\hline least $25 \%$ of the time & $22(37.3)$ \\
\hline Feeling of incomplete evacuation & $29(49.2)$ \\
\hline Manual assistance at defecation & $11(18.6)$ \\
\hline Digital removal of feces & $5(8.5)$ \\
\hline Sensation of anorectal obstruction & $9(15.3)$ \\
\hline Urge incontinence & $17(28.8)$ \\
\hline Unnoticed incontinence & $10(16.9)$ \\
\hline Fecal incontinence for liquid stool & $11(18.6)$ \\
\hline Fecal incontinence for solid stool & $3(5.1)$ \\
\hline
\end{tabular}

$\mathrm{IQR}=$ Interquartile range; $\mathrm{BMI}$ = body mass index.

a $\mathrm{BMI}$ of women in the normal population is 18-24.

b 59 women delivered 152 children; none were nullipara.

${ }^{c}$ Point D was not correctly measured in all cases and was excluded from the study. 
Table 2. Findings at AFT in patients with primary POP compared to healthy controls

\begin{tabular}{lccccc}
\hline $\begin{array}{l}\text { Anorectal funtion } \\
\text { parameters }\end{array}$ & \multicolumn{2}{c}{ Patients with POP $(\mathrm{n}=59)$} & \multicolumn{2}{l}{$\begin{array}{l}\text { Reference values } \\
\text { (healthy controls) }\end{array}$} & p value and 95\% CI \\
\cline { 2 - 4 } & mean $\pm \mathrm{SD}$ & median & IQR & $35-70$ & $0.37 ;-3.08$ to 7.99 \\
\hline Resting pressure, mm Hg & $55.46 \pm 21.24$ & 54.00 & 30 & $140-220$ & $<0.001 ;-80.87$ to -58.62 \\
Squeezing pressure, mm Hg & $110.25 \pm 42.70$ & 116.00 & 53 & $30-50$ & $<0.001 ; 25.6$ to 40.76 \\
First sensation, ml & $76.19 \pm 40.58$ & 80.00 & 60 & $70-150$ & $0.006 ; 6.92$ to 40.03 \\
First desire, ml & $133.47 \pm 65.53$ & 130.00 & 80 & $200-500$ & $<0.001 ;-160.60$ to -116.14 \\
Capacity, ml & $211.63 \pm 85.30$ & 190.00 & 90 & $<10$ & $<0.001 ; 1.94$ to 3.56 \\
Anal sensibility, mA & $7.74 \pm 3.08$ & 7.00 & 2.0 & $<34$ & $<0.001 ; 8.74$ to 15.33 \\
Rectal sensibility, mA & $29.03 \pm 12.42$ & 30.00 & 16.0 & $2.0 \pm 0.2$ & $0.0002 ; 0.07$ to 0.32 \\
PNTLT (r.s.), ms & $2.20 \pm 0.44$ & 2.2 & 0.7 & $2.0 \pm 0.2$ & $<0.001 ; 0.21$ to 0.54 \\
PNTLT (l.s.), ms & $2.39 \pm 0.59$ & 2.2 & 0.4 & & \\
\hline
\end{tabular}

$\mathrm{IQR}=$ Interquartile range; 1. s. = left side; r.s. = right side.

Table 3. Decline in squeezing and resting pressure by age and parity

\begin{tabular}{|c|c|c|c|c|}
\hline & \multicolumn{2}{|l|}{ Squeezing pressure } & \multicolumn{2}{|l|}{ Resting pressure } \\
\hline & coefficient $(95 \% \mathrm{CI})$ & $\mathrm{p}$ value & coefficient $(95 \% \mathrm{CI})$ & $\mathrm{p}$ value \\
\hline Constant & 142.07 & $<0.001$ & 73.21 & $<0.001$ \\
\hline $45-55$ years $^{1}$ & $-3.07(-40.05$ to 33.94$)$ & 0.87 & $-7.12(-25.53$ to 11.30$)$ & 0.44 \\
\hline $55-65$ years & $-17.16(-55.40$ to 21.07$)$ & 0.37 & $-7.94(-26.97$ to 11.10$)$ & 0.40 \\
\hline$\geq 65$ years & $-14.56(-58.55$ to 29.44$)$ & 0.51 & $-15.31(-37.21$ to 6.59$)$ & 0.17 \\
\hline Parity & $-8.96(-21.21$ to 3.28$)$ & 0.15 & $-3.88(-9.98$ to 2.22$)$ & 0.21 \\
\hline
\end{tabular}

${ }^{1}$ Compared to $35-45$ years as reference.

First sensation, first desire and capacity were unrelated to the stage of posterior wall prolapse (all $p \geq 0.27$ ). No relation existed between anal and rectal sensitivity or PNTLT and the stage of posterior wall prolapse (all $\mathrm{p}>$ $0.11)$.

Table 3 shows the effects of age and parity upon squeezing and resting pressure. On average, the squeezing and resting pressure were reduced with 14.56 and $15.31 \mathrm{~mm} \mathrm{Hg}$, respectively, for women of 65 years and older compared to women at the age of 35-45 years. The declines in squeezing and resting pressure appeared not to be significant.

Increased age and parity did not have an effect upon the volumetry and the electromyography parameters.

Table 4 shows the results of AFT in patients with primary POP with and without defecation symptoms. Patients with complaints of fecal incontinence had significantly lower resting and squeezing pressures than pa- tients without fecal incontinence. There were no significant differences in manometric findings between patients with and without constipation.

No relation was found between constipation or fecal incontinence and the stage of posterior wall prolapse $(\mathrm{p}=0.07$ and $\mathrm{p}=0.68$, respectively).

Figure 1 shows the relation between the squeezing pressure evaluated at digital rectal examination and at manometric assessment. Absent, decreased and normal squeezing pressures assessed at digital rectal examination were significantly positively associated with the squeezing pressures measured at manometric testing $(\mathrm{p}=0.001)$. The mean $\pm \mathrm{SD}$ squeezing pressures in these 3 groups were $60.75 \pm 22.24 \mathrm{~mm} \mathrm{Hg}$ (absent group), $94.71 \pm 34.36 \mathrm{~mm} \mathrm{Hg}$ (decreased group) and $125.68 \pm$ $41.81 \mathrm{~mm} \mathrm{Hg}$ (normal group).

Anal endosonography revealed 7 defects $(12 \%, 7 / 57)$ and 4 suspected defects $(7 \%, 4 / 57)$ of the external anal 
Table 4. Comparison of findings at AFT in patients with and without defecation complaints

\begin{tabular}{|c|c|c|c|c|c|c|}
\hline Anorectal function parameters & $\begin{array}{l}\text { POP without } \\
\text { constipation } \\
(n=29)\end{array}$ & $\begin{array}{l}\text { POP with } \\
\text { constipation } \\
(\mathrm{n}=30)\end{array}$ & $\mathrm{p}$ value & $\begin{array}{l}\text { POP without fecal } \\
\text { incontinence } \\
(\mathrm{n}=37)\end{array}$ & $\begin{array}{l}\text { POP with fecal } \\
\text { incontinence } \\
(\mathrm{n}=22)\end{array}$ & $\mathrm{p}$ value \\
\hline Resting pressure, $\mathrm{mm} \mathrm{Hg}$ & $57.90 \pm 25.47$ & $53.10 \pm 16.24$ & 0.39 & $59.98 \pm 21.27$ & $48.00 \pm 19.41$ & 0.036 \\
\hline Squeezing pressure, $\mathrm{mm} \mathrm{Hg}$ & $109.28 \pm 39.75$ & $111.20 \pm 46.03$ & 0.86 & $118.76 \pm 35.95$ & $95.95 \pm 49.79$ & 0.046 \\
\hline First sensation, $\mathrm{ml}$ & $82.41 \pm 36.02$ & $70.17 \pm .44 .32$ & 0.25 & $80.14 \pm 37.12$ & $69.55 \pm 45.95$ & 0.33 \\
\hline First desire, $\mathrm{ml}$ & $142.07 \pm 71.33$ & $125.17 \pm 54.90$ & 0.31 & $138.65 \pm 65.66$ & $124.77 \pm 60.24$ & 0.42 \\
\hline Capacity, ml & $213.79 \pm 78.89$ & $209.53 \pm 92.39$ & 0.85 & $228.27 \pm 87.05$ & $183.64 \pm 76.11$ & 0.051 \\
\hline Anal sensibility, $\mathrm{mA}$ & $8.31 \pm 3.73$ & $7.18 \pm 2.18$ & 0.16 & $7.92 \pm 3.29$ & $7.43 \pm 2.71$ & 0.54 \\
\hline Rectal sensibility, $\mathrm{mA}$ & $28.63 \pm 11.37$ & $29.43 \pm 13.54$ & 0.81 & $26.97 \pm 12.44$ & $32.58 \pm 11.84$ & 0.09 \\
\hline PNTLT (r.s.), ms & $2.17 \pm 0.42$ & $2.21 \pm 0.46$ & 0.70 & $2.23 \pm 0.45$ & $2.12 \pm 0.42$ & 0.38 \\
\hline PNTLT (1.s.), ms & $2.27 \pm 0.40$ & $2.48 \pm 0.72$ & 0.22 & $2.35 \pm 0.64$ & $2.41 \pm 0.48$ & 0.72 \\
\hline
\end{tabular}

l.s. = Left side; r.s. = right side.

sphincter; a defect of the internal anal sphincter was found in 5 patients $(9 \%, 5 / 57)$ and a suspected defect in 3 patients $(5 \%, 3 / 57)$.

The sensitivity of digital rectal examination for external sphincter defects was $8 / 11(0.73,95 \%$ CI $0.39-0.94)$ and the specificity was $29 / 46(0.63,95 \%$ CI $0.48-0.76)$. The proportion of correct test results was $37 / 57(0.65$, 95\% CI 0.51-0.77), PV+ was 8/25 (0.32, 95\% CI 0.15-0.53) and PV- was 29/32 (0.91, 95\% CI 0.75-0.98) (table 5).

In 3 subjects the squeezing pressure at digital rectal examination was normal, while anal endosonography revealed 2 real defects and 1 suspected defect of the external anal sphincter.

Table 6 shows the relation between fecal incontinence and a defect of the external sphincter. Complaints of fecal incontinence were associated with a higher risk of (suspected) external sphincter defects (OR 12.75, $\mathrm{p}=0.003$, 95\% CI 2.40-66.67). The risk of a sphincter defect further increased when sphincter pressure at digital rectal examination was absent or decreased (OR 22.75, $\mathrm{p}=0.01,95 \%$ CI 2.11-250.0).

\section{Discussion}

In our group of patients with primary POP, the 2 most frequent defecation disorders were feeling of incomplete defecation and urge incontinence. No relation was found between any of the defecation disorders and the stage of posterior vaginal wall prolapse. We found physiologic differences between the healthy controls and the patient group as a significantly reduced squeezing pressure, an

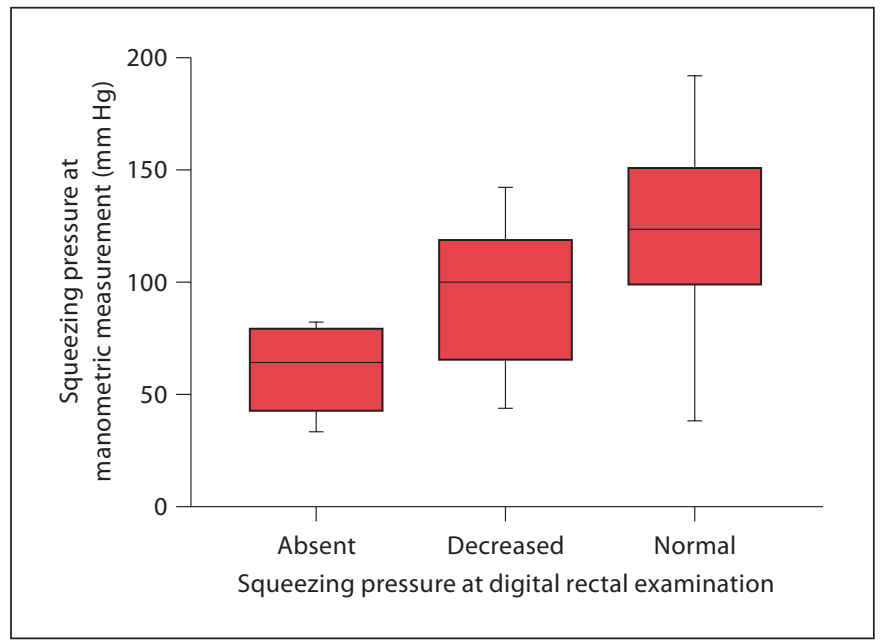

Fig. 1. Relation between squeezing pressure at digital rectal examination and at manometric assessment in 57 patients. The thick bars denote the means, the boxes denote the interquartile ranges and the error bars denote the total ranges.

increased volume for first sensation and a reduced mean rectal capacity in the patient group. Other important findings were reduced anal and rectal sensibility and a significantly prolonged PNTLT for both sides compared to the healthy controls. No differences in the outcome of anorectal function testing were found between patients with and without constipation, nor did we find a relation with the stage of posterior vaginal wall prolapse. Patients with fecal incontinence had a significantly lower resting and squeezing pressure compared to patients without fecal incontinence. Absent, decreased and normal squeez- 
Table 5. Relation between external anal sphincter defect at anal endosonography and squeezing pressure at digital rectal examination

\begin{tabular}{llll}
\hline Digital rectal examination & $\begin{array}{l}\text { (Possible) external } \\
\text { sphincter defect at } \\
\text { anal endosonography }\end{array}$ & $\begin{array}{l}\text { No external sphincter } \\
\text { defect at anal } \\
\text { endosonography }\end{array}$ & Total \\
\hline Weak/absent squeezing pressure $^{1}$ & 8 & 17 & 25 \\
Normal squeezing pressure $^{1}$ & 3 & 29 & 32 \\
Total & 11 & 46 & 57 \\
\hline
\end{tabular}

${ }^{1} 2$ missing cases.

Table 6. Relation between fecal incontinence in combination with sphincter pressure at digital rectal examination and (suspected) external sphincter defect at anal endosonography

\begin{tabular}{lllll}
\hline Digital rectal examination & & $\begin{array}{l}\text { (Possible) external } \\
\text { sphincter defect }^{2}\end{array}$ & $\begin{array}{l}\text { No external } \\
\text { sphincter defect }\end{array}$ & Total \\
\hline Weak/absent squeezing pressure $^{1}$ & Fecal incontinence & 7 & 4 & 11 \\
& No fecal incontinence & 1 & 13 & 14 \\
Normal squeezing pressure $^{1}$ & Fecal incontinence & 2 & 8 & 10 \\
& No fecal incontinence & 1 & 21 & 22 \\
\hline Total & & 11 & 46 & 57 \\
\hline
\end{tabular}

${ }^{1}$ At digital rectal examination. ${ }^{2}$ At anal endosonography.

ing pressure assessed at digital rectal examination were significantly positively associated with the squeezing pressure values measured at manometric testing, but the predictive value of digital rectal examination for defects of the anal external sphincter was low compared with anal endosonography as golden standard. We observed in $19 \%$ of our population a defect (or suspected defect) of the external sphincter and in $14 \%$ a (suspected) defect of the internal sphincter by anal endosonography.

Our study may have some limitations. First, potential bias could be caused by the reference values for anorectal manometry as the composition of the selected reference group did not exactly match our patient group with respect to age and parity. Several studies reported age- and parity-related effects upon squeezing pressure. A study by McHugh and Diamant [12] showed that aging in women was associated with a significant $6 \%$ reduction in squeezing pressure in the sixth decade and a $37 \%$ reduction after the eighth decade, in comparison to women in their third decade [12]. We observed an age- and parityrelated diminished squeezing pressure. However, in agreement with several other studies, this decline was not significant $[13,14]$.
A second drawback referred to the sample size. Possibly, the power of our study was low given the relatively small study population that could have influenced our results. Including more patients was initially not feasible because of the inconvenience of the diagnostic tests. Lack of power (small sample size) was no issue (table 3). To detect a significant difference in resting pressure between the control and study group, one would need at least 318 patients to detect a mean difference of $2.96 \mathrm{~mm} \mathrm{Hg}$.

Another concern was the open unblinded measurement of AFT. AFT was carried out by experienced examiners by means of a standard protocol. The examiner who performed AFT at the second visit received clinical information from the examiner at the first visit. If anything, this type of information exchange would strengthen correlations, but in fact the reverse was true: no relation between the stage of posterior wall prolapse and the results of AFT was found. Hence, it is unlikely that information bias affected our results.

Constipation and obstructed defecation are frequently reported in patients with POP, but it remains questionable if the bowel disorders are directly related to the posterior wall prolapse, i.e. rectocele. Our study sup- 
ports the findings of previous research showing no association between bowel dysfunction and stage of POP [15-17] and that there are no major physiological differences by AFT between patients with symptomatic rectocele, asymptomatic rectocele and patients without rectocele $[18,19]$. Our study could not confirm the finding by Siproudhis et al. [20,21], who reported that constipation in patients with rectocele may be related to higher rectal volumes.

In agreement with the study by Dobben et al. [22], we found that squeezing pressure at digital rectal examination significantly correlates with the squeezing pressure at anorectal manometric testing. Studies in which the condition of the external sphincter in patients with POP was routinely assessed are scarce. The prevalence of external sphincter defects in our study (19\%) was comparable with those reported by Da Silva et al. (21.9\%) [10]. As reference standard for external sphincter condition we used anal endosonography. Although endoanal MR imaging is often recommended as the optimal test for the detection of sphincter defects, a recent study of Dobben et al. [23] showed that both endoanal MR imaging and anal endosonography are sensitive tools and that both techniques can be used to depict surgically repairable anterior external defects.

Defecation disorders often occur in women with primary POP. When these complaints are bothersome, a diagnostic approach seems justified. Most of the manometric findings were out of the normal range, indicating the presence of neuromuscular damage of the anorectal region. The neuromuscular damage was unrelated to constipation problems and the degree of posterior vaginal wall prolapse, but was expressed in reduced sphincter pressures resulting in a higher risk of fecal incontinence. For obstructed defecation, other causes, such as pelvic floor dyssynergia, mucosal intussusception, rectal prolapse or solitary ulcer syndrome, have to be considered [24].

Overall we conclude that AFT is of limited use in the routine diagnostic work-up of patients with primary POP as it has no discriminative value between women with and without constipation. Only in patients with fecal incontinence complaints, we recommend AFT in combination with anal endosonography to differentiate between functional and anatomical problems of the anal external sphincter.

\section{References}

1 Digesu GA, Chaliha C, Salvatore S, Hutchings $\mathrm{A}$, Khullar V: The relationship of vaginal prolapse severity to symptoms and quality of life. BJOG 2005;112:971-976.

$\checkmark 2$ Spence-Jones C, Kamm MA, Henry MM, Hudson CN: Bowel dysfunction: a pathogenic factor in uterovaginal prolapse and urinary stress incontinence. BJOG 1994;101: 147-152.

3 Diamant NE, Kamm MA, Wald A, Whitehead WE; American Gastroenterology Association: AGA technical review on anorectal testing techniques. Gastroenterology 1999; 116:735-760.

-4 Weber AM, Abrams P, Brubaker L, Cundiff G, Davis G, Dmochowski RR, Fisher J, Hull T, Nygaard I, Weidner AC: The standardization of terminology for researchers in female pelvic floor disorders. Int Urogynecol J 2001; 12:178-186.

5 Weber AM, Buchsbaum GM, Chen B, Clark AL, Damaser MS, Daneshgari F, Davis G, DeLancey J, Kenton K, Weidner AC, Word RA: Basic science and translation research in female pelvic floor disorders: proceedings of an NIH sponsored meeting. Neurourol Urodyn 2004;23:288-301.

\footnotetext{
6 Bump RC, Mattiasson A, Bo K, Brubaker LP, 11 Sun WM, Read NW: Anorectal function in DeLancey JO, Klarskov P, Shull BL, Smith AR: The standardization of terminology of female pelvic organ prolapse and pelvic floor dysfunction. Am J Obstet Gynecol 1996;175: $10-17$.

7 Brummen HJ, Bruinse HW, van der Pol G, Heintz AP, van der Vaart CH: Defecatory symptoms during and after the first pregnancy: prevalences and associated factors. Int Urogynecol J 2006;17:224-230.

8 Van Der Vaart CH, De Leeuw JR, Roovers JP, Heintz AP: Measuring health related quality of life in women with urogenital dysfunction: The urogenital distress inventory and incontinence impact questionnaire revisited. Neurourol Urodyn 2003;22:97-104.

-9 Bradley CS, Nygaard IE, Brown MB, Gutman, RE, Kenton KS, Whitehead WE, Goode PS, Wren PA, Ghetti C, Weber AM; Pelvic Floor Disorders Network: Bowel symptoms in women 1 year after sacrocolpopexy. Am J Obstet Gynecol 2007;197:642.e1-642.e8.

10 Da Silva GM, Gurland B, Sleemi A, Levy G: Posterior vaginal wall prolapse does not correlate with fecal symptoms or objective measures of anorectal function. Am J Obstetric Gynecol 2006;195:1742-1747. normal human subjects: effect of gender. Int J Colorectal Dis 1989;4:188-196.

12 McHugh SM, Diamant NE: Effect of age, gender, and parity on anal canal pressures. Contribution of impaired anal sphincter function to fecal incontinence. Dig Dis Sci 1987;32:726-736.

13 Cali R, Blatchford GJ, Perry RE, Pitsch RM, Thorson AG, Christensen MA: Normal variation in anorectal manometry. Dis Colon Rectum 1992;35:1161-1164.

14 Loening-Baucke V, Anuras S: Effects of age and sex on anorectal manometry. Am J Gastroenterol 1985;80:50-53.

15 Jelovsek JE, Barber MD, Paraiso MF, Walter MD: Functional bowel and anorectal disorders in patients with pelvic organ prolapse and incontinence. Am J Obstet Gynecol 2005; 193:2105-2111.

16 Kahn MA, Breitkopf CR, Valley MT, Woodman PJ, O'Boyle AL, Bland DI, Schaffer JI, Grady JJ, Swift SE: Pelvic Organ Support Study (POSST) and bowel symptoms: straining at stool is associated with perineal and anterior vaginal descent in a general gynecologic population. Am J Obstet Gynecol 2005; 192;1516-1522.
} 
17 Burrows LJ, Meyn LA, Walters MD, Weber AM: Pelvic symptoms in women with pelvic organ prolapse. Obstet Gynecol 2004;104; 982-988.

- 18 Yoshioka K, Matsui Y, Yamada O, Sakaguchi M, Takada H, Hioki K, Yamamoto M, Kitada M, Sawaraga I: Physiologic and anatomic assessment of patients with rectocele. Dis Colon Rectum 1991;34:704-708.

19 Felt-Bersma RJ, Sloots CE, Poen AC, Cuesta MA, Meuwissen SG: Rectal compliance as routine measurement: extreme values have direct clinical impact and normal volumes exclude rectum as a problem. Dis Colon Rectum 2000;43:1732-1738.
20 Siproudhis L, Ropert A, Violette J, Bretagne JF, Heresbach D, Raoul JL, Gosselin M: How accurate is clinical examination in diagnosing and quantifying pelvirectal disorders? A prospective study in a group of 50 patients complaining of defecatory difficulties. Dis Colon Rectum 1993;36:430-438.

21 Siproudhis L, Ropert A, Lucas J, Raoul JL, Heresbach D, Bretagne JF, Gosselin M: Defecatory disorders, anorectal and pelvic floor dysfunction: a polygamy? Radiologic and manometric studies in 41 patients. Int J Colorect Dis 1992;7:102-107.
22 Dobben AC, Terra MP, Deutekom M, Gerhards MF, Bijnen AB, Felt-Bersma, Janssen LWM, Bossuyt PMM, Stoker J: Anal Inspection and digital rectal examination compared to anaorectal physiologic tests and endoanal ultrasonography in evaluating fecal incontinence. Int J Colorectal Dis 2007;22: 783-790.

23 Dobben AC, Terra MP, Slors JF, Deutekom M, Gerhards MF, Beets-Tan RG, Bossuyt PM, Stoker J: External anal sphincter defects in patients with fecal incontinence: comparison of endoanal MR imaging and endoanal US. Radiology 2007;242:463-471.

-24 Pescatori M, Spyrou M, Pulvirenti d'Urso A: A prospective evaluation of occult disorders in obstructed defecation using the 'iceberg diagram'. Colorect Dis 2007;9:452-456. 